\title{
1 FITNESS LANDSCAPES REVEAL CONTEXT-DEPENDENT BENEFITS OF OVIPOSITION CHOICE
}

2 Vrinda Ravi Kumar ${ }^{1 *}$, Gaurav Agavekar ${ }^{1,2}$ and Deepa Agashe ${ }^{1 *}$

$4 \quad{ }^{1}$ National Centre for Biological Sciences, Tata Institute of Fundamental Research, Bangalore, India

$5 \quad{ }^{2}$ Current address: Okinawa Institute of Science and Technology (OIST), Japan

$7 \quad{ }^{*}$ Correspondence:

$8 \quad$ vrindark@ncbs.res.in

9 dagashe@ncbs.res.in

\section{ABSTRACT}

12 Resource choice behaviour has enormous fitness consequences and can drive niche expansion.

13 However, individual behavioural choices are often mediated by past experience. Are such context-

14 dependent behaviours adaptive? Using the red flour beetle, we demonstrate that context-dependent 15 oviposition choice indeed reflects distinct, context-specific local fitness peaks. Manipulating female egg 16 allocation in a habitat containing optimal and novel resource patches, we measured offspring fitness to generate fitness landscapes as a function of all possible oviposition behaviours (i.e. combinations of fecundity and resource preference). Females from different age and density contexts exhibit distinct behaviours that optimize different fitness components. With increasing age and experienced population density, they produce few but fast-developing offspring that are advantageous under high resource competition; whereas young naïve females produce many slow-developing offspring, which is beneficial under weak competition. Systematically mapping complete context-dependent fitness landscapes is thus critical to infer behavioural optimality, and offers predictive power in novel contexts.

25 Keywords - optimal choice, context-dependence, female oviposition, resource preference, 26 heterogeneous habitat 
bioRxiv preprint doi: https://doi.org/10.1101/2021.05.27.445916; this version posted May 28, 2021. The copyright holder for this preprint (which was not certified by peer review) is the author/funder, who has granted bioRxiv a license to display the preprint in perpetuity. It is made available under aCC-BY-NC-ND 4.0 International license.

\section{INTRODUCTION}

Organisms often encounter heterogeneous habitats, and their behavioural choices in such situations ultimately determine their fitness. This is perhaps best exemplified by females' reproductive decisions when faced with alternate resources. For example, females of phytophagous insects can lay eggs on different host plants, affecting offspring survival and growth and determining their reproductive success (Jaenike 1978; Craig \& Itami 2008; Gripenberg et al. 2010; Charlery de la Masselière et al. 2017). Therefore, oviposition preference is predicted to face strong selection on par with other life history traits (Resetarits Jr. 1996), which may result in strong preference hierarchies across alternate resources (Gripenberg et al. 2010). However, oviposition choice often varies dramatically with females' prior experience, reflecting the ecological or internal context determined by their environment or life history (Anderson \& Anton 2014). For instance, females of the polyphagous moth Spodoptera littoralis that develop on a specific host plant as larvae also prefer it for oviposition (Proffit et al. 2015). More generally, in many species, ecological factors such as age and resource competition change across individuals' lifespan, altering key components of oviposition behaviour such as fecundity (mammals - Sand 1996; Coulson et al. 2000; fish - Bobko \& Berkeley 2004, Karjalainen et al. 2016; insects - Barnes et al. 2008; Berggreen et al. 2018; Khan et al. 2018) and oviposition choice (Resetarits Jr. \& Wilbur 1989; Yoshioka et al. 2012; Raitanen et al. 2014). Given the potentially enormous range of contexts experienced by different individuals across generations, how do context-dependent oviposition behaviours evolve?

To address this question, we must understand what kinds of selection pressures may drive contextspecific oviposition choice. Female choice may evolve under strong selection for a single globally optimal preference, with deviations reflecting either weak selection or females' inability to behave optimally in specific contexts. For instance, limited perception of resource quality (Bernays 1998, 2001) or other search-related constraints (Thompson 1988; Gripenberg et al. 2010; Wood et al. 2018) can prevent females from accessing an adaptive resource (Price 2003). Optimal behaviour may also be limited by tradeoffs between maternal and offspring fitness (e.g., Garcia-Robledo 2012), or by the 
54 presence of competitors or predators (e.g., Resetarits Jr. \& Wilbur 1989; Rieger et al. 2004; Binckley \&

55 Resetarits Jr. 2008; Touchon \& Worley 2015). A second possibility is that context-specific female choice 56 reflects context-specific selection to optimize distinct fitness peaks. In other words, female choice in 57 each context may be perfectly attuned to optimality in that context (e.g. Dvorak \& Gvozdik 2010). However, to our knowledge, no study has distinguished between these alternative hypotheses, by connecting past context to future fitness. In addition, it is critical to measure multiple fitness components to identify context-specific fitness optima, because multiple traits contribute to fitness and may trade off with each other (Schluter et al. 1991; Walsh \& Blows 2009; Lailvaux \& Kasumovic 2011; Taff et al. 2012). Finally, most studies are restricted to analysing females from a limited set of prior contexts, in which only a subset of possible behaviours are expressed. As a result, they only sample a part of the full behavioural fitness landscape, making it difficult to infer whether a specific observed behaviour is locally adaptive or globally maladaptive. Ideally, we need to generate landscapes that encompass all possible behavioural choices, including those outside the range of observed behaviours. An added advantage of such landscapes is that we gain the ability to predict female fitness in novel contexts, based only on information about their oviposition behaviour. Illuminating the entire phenotypic fitness landscape is thus critical to understand the evolution of context-dependent female oviposition behaviour.

We created such fitness landscapes for the red flour beetle Tribolium castaneum, a widespread generalist pest of cereal flours that has long served as a model system in ecology and evolutionary biology (Sokoloff 1972, 1974, 1977; Pointer et al. 2021). Prior work demonstrates significant variation in key oviposition behaviours such as fecundity and resource preference, modulated by age and population density (indicating strength of resource competition). Here, we explicitly connect prior female context, behavioural choice, and fitness, by conducting three sets of experiments focused on a choice between an optimal resource (wheat flour) and a suboptimal resource (finger millet flour) (Figure 1). To test the impact of context on behaviour, we first measured oviposition behaviour (fecundity and preference) of females from six different age and density contexts (Experiment 1). Second, we 
possible oviposition choices. To do this, we experimentally manipulated egg allocation in a habitat with

both resource patches, and measured multiple components of offspring fitness (Experiment 2). Finally,

we validated the fitness landscape by jointly measuring oviposition behaviours and consequent offspring

fitness for females from three different contexts (Experiment 3). By placing oviposition behaviour in a

comprehensive fitness landscape, we demonstrate that divergent, context-dependent oviposition

behaviours could evolve via selection driving females towards context-specific local adaptive peaks for

distinct fitness components.

\section{METHODS}

\section{Population maintenance}

We derived experimental individuals from large, outbred laboratory "stock" populations of T. castaneum

(Ravi Kumar et al. 2018), maintained with $\sim 2500-5000$ adults in $750 \mathrm{~g}$ whole wheat flour. To propagate

stocks, we introduced $\sim 3000$ adults into fresh wheat flour, removed adults after 1 day of oviposition,

allowed the next generation to develop for 5-6 weeks, and used the adults to repeat the cycle. We held

all populations and experimental individuals at $33 \pm 2^{\circ} \mathrm{C}$ in a dark incubator, except during experimental

handling under white light at room temperature (never exceeding 1 hour). Flour beetles have highest fitness in wheat flour and show significantly slower development in finger millet flour ( $37 \%$ slower development relative to wheat) (Ravi Kumar et al. 2018). Hence, we refer to wheat flour as the optimal resource, and finger millet as the suboptimal alternative resource. To remove any prior infestation, we cold-sterilized flour for at least 4 hours at $-80^{\circ} \mathrm{C}$ before use.

102

\section{Collecting females from different age and density contexts}

As required for different experiments (Figure 1), we generated females from six distinct age and density contexts. Females become sexually mature within one week of eclosion and lay eggs continuously for at least 40 weeks (Good 1936; Sokoloff 1974). However, fertility begins to decline starkly $\sim 7$ weeks post 
weeks and $\sim 6$ weeks post-eclosion respectively, corresponding to an approximately $27 \%$ decline in

fertility (measured for isolated, singly-mated females; Khan et al. 2018). For low density (“LD”) contexts

we held females in isolation or with a single male (depending on their prior mating experience), whereas

high density (“HD”) females were taken directly from stock populations. Thus, females from each context

were mated with males from the same context. For the two "aged" contexts, after the first oviposition

in LD conditions. Further details are given in SI methods.

\section{Measuring oviposition preference and offspring fitness}

We measured the oviposition preference of each female (Figure 1, Experiment 1; regardless of her prior

context) for wheat vs. finger millet flour in 2-choice assays, in identical conditions. Briefly, we released each female in the center of a $60 \mathrm{~mm}$ Petridish containing a patch of each resource $(\sim 1 \mathrm{~g})$ on opposite ends (Figure S1; SI methods). After 45 hours (before eggs start hatching), we removed the female and counted the number of eggs in each resource patch. We used the total number of eggs in the habitat

(i.e. across both resource patches) to quantify fecundity, and the percentage of eggs deposited in finger millet as a measure for oviposition preference for finger millet. In control assays (with both patches of the same resource), we confirmed that females did not exhibit any side preference (Figure S2).

To measure the fitness consequences of female oviposition behaviours (Figure 1, Experiment 3), we allowed offspring to develop in the respective resource patches undisturbed for 21 days. Larvae could move across resource patches during development. We quantified offspring fitness as the proportion of eggs that survived three weeks of development ("survival"), the proportion of offspring that had resource patches. 
bioRxiv preprint doi: https://doi.org/10.1101/2021.05.27.445916; this version posted May 28, 2021. The copyright holder for this preprint (which was not certified by peer review) is the author/funder, who has granted bioRxiv a license to display the preprint in perpetuity. It is made available under aCC-BY-NC-ND 4.0 International license.

135 To generate complete fitness landscapes (Figure 1, Experiment 2), we had to quantify the impact of the entire range of possible oviposition behaviours on offspring fitness. Hence, we collected females from three different contexts with distinct ranges of fecundity (young LD, young HD and old HD; see Results);

138 but we did not allow them to express their oviposition choice. Instead, we placed each female in $\sim 2 \mathrm{~g}$ wheat flour (43-45 hours in a $60 \mathrm{~mm}$ petri-plate), collected the eggs, and manipulated egg allocation systematically across wheat and finger millet patches in a 2-patch habitat (as in the oviposition choice assays), mimicking the range of possible oviposition preferences ( $n=16-20$ females per allocation). By

142 distributing females with various fecundity values across egg allocation treatments, we dissociated 143 female fecundity from resource preference. We measured fitness for each female as described above.

Using these data, we generated fitness landscapes for each fitness component as a function of female 146 fecundity (observed) and 'preference' for finger millet (manipulated egg allocation). To generate a 147 smooth fitness landscape for each fitness component, we extrapolated fitness values using local 148 smoothing ('loess') by estimating the value of the three fitness measures for all possible combinations 149 of female fecundity and oviposition preference using the 'panel.2dsmoother' function (from the 150 latticeExtra package, Sarkar 2019) in the levelplot function (lattice package, Sarkar 2008). Fitness was 151 evaluated in an equally spaced grid of 20 by 20 points across the sampled range of fecundity and 152 preference. Thus, we generated fitness landscapes that allowed us to estimate the fitness consequences of any given combination of fecundity and oviposition preference.

To validate fitness predictions from the fitness landscape (Figure 1, Experiment 3), we allowed females from three different contexts (young LD, young HD and old HD) to make oviposition choices; counted and returned eggs to the patch in which they were laid; and measured offspring fitness for each female. Using the median values of observed fecundity and preference for females from each context, we predicted their offspring fitness based on the fitness landscape, and compared the predicted fitness values with the median observed fitness values. 
bioRxiv preprint doi: https://doi.org/10.1101/2021.05.27.445916; this version posted May 28, 2021. The copyright holder for this preprint (which

was not certified by peer review) is the author/funder, who has granted bioRxiv a license to display the preprint in perpetuity. It is made available under aCC-BY-NC-ND 4.0 International license.

\section{Statistical analysis}

163 All analyses were conducted using R (R Core Team 2017) in RStudio (RStudio Team 2020). We statistically modelled the impact of age and density on female fecundity and of age, density and fecundity on oviposition preference (Experiment 1) and the impact of context, fecundity, and manipulated egg generalised linear models with binomially distributed errors ('binomial GLM') for female oviposition preference, offspring survival and development rate; and a GLM with Poisson errors ('Poisson GLM') for the total number of offspring. In each case, we first fit the maximal model with main effects and all possible interaction terms, and then used the 'stepAIC' function from the 'MASS' package (Venables 2002) to simplify the maximal model. Further details are in the SI methods.

\section{RESULTS}

\section{Prior context alters female oviposition behaviour}

176 Based on earlier work, we expected that female age and experienced population density (an indicator of resource competition) would impact oviposition behaviour, i.e. female fecundity and preference for the novel finger millet resource (Figure 1, Experiment 1). As expected, female fecundity decreased with age and experience with high population density ("HD”) (Figure 2A, Table 1A). Young females at low density ("LD”) had the highest fecundity, whereas HD females of the same age laid only about half as many eggs, similar to mid-aged and older females that experienced HD throughout their adult life. This effect of age was consistent when the same set of young females were allowed to age (Figure S3); and in an independent experimental block with young LD, young HD and old HD females (Figure S4).

Concomitant with fecundity, oviposition preference for finger millet also decreased with age and density (Figure 2B, Table 1B), except for old HD females which oviposited randomly. Combining data across contexts, females with high fecundity laid more eggs in finger millet (Spearman's rho $=0.303, p<0.001$; 
bioRxiv preprint doi: https://doi.org/10.1101/2021.05.27.445916; this version posted May 28, 2021. The copyright holder for this preprint (which was not certified by peer review) is the author/funder, who has granted bioRxiv a license to display the preprint in perpetuity. It is made available under aCC-BY-NC-ND 4.0 International license.

female context (except for aged LD females; see Figure S6 for additional experimental blocks), indicating more complex interactions between age, fecundity, and density (Table 1B, Figure S5). For instance, the relationship between fecundity and preference depended on competition. Under low density, preference for finger millet increased with fecundity; but females from a high-density context did not change their preference as fecundity increased (Figure S5F). Similarly, competition had opposite impacts on how young vs. old females allocate their eggs (Figure S5G). Under low density, old females became more conservative in resource use (relative to young females); whereas under high density, older females were more likely to prefer the new resource (finger millet).

The changing preference of young HD females when allowed to age under low density presents an interesting case. These females continued to show a strong preference for wheat (typical of HD females) despite experiencing LD for 4 weeks (compare young HD vs. aged, Figure 2B), and also failed to exhibit the high fecundity that is commonly observed at low density (Figure 2A). Thus, the impact of early experience with HD seemed to last for a very long time. Another interesting group is old HD females, who did not prefer wheat as predicted by the age- and density- dependent trends in other females. Hence, preference may shift non-monotonically as females experience high density for different time intervals. Nonetheless, it is clear that age and density present appropriate contexts that influence two key components of oviposition behaviour. Therefore, we proceeded with measuring the fitness consequences of these divergent context-dependent resource preference behaviours.

\section{Fitness landscapes predict consequences of divergent oviposition behaviour}

To quantify the impact of the full range of potential oviposition choices on fitness (Figure 1, Experiment 2), we allowed females to lay eggs in wheat and then manually distributed each female's eggs in wheat and finger millet patches. To include the widest possible range of fecundity (Figure 2A), we sampled females from three different contexts (young LD, young HD, and old HD females), and measured three metrics of offspring fitness (Figure S7). Across female contexts, offspring survival was largely invariable ( $75 \%$ offspring survived). However, young LD females produced twice as many offspring as females 
bioRxiv preprint doi: https://doi.org/10.1101/2021.05.27.445916; this version posted May 28, 2021. The copyright holder for this preprint (which was not certified by peer review) is the author/funder, who has granted bioRxiv a license to display the preprint in perpetuity. It is made available under aCC-BY-NC-ND 4.0 International license.

216 from other contexts ( 20 vs. $\sim 10$ per female), although they had the slowest development $(\sim 25 \%$ 217 offspring completed pupation in 3 weeks, vs. $~ 50-75 \%$ for young HD and old HD females). Thus, distinct 218 oviposition behaviours associated with different female contexts can dramatically alter offspring fitness 219 (see results of statistical modelling, Table 1C, Figures S8-S10). Notably, offspring development rate was strongly negatively correlated with female fecundity as well as total offspring (Figure 3A-B, Figure S8D), reflecting a well-known density-regulated tradeoff between offspring number and development in this species (Sokoloff 1974).

To visualize the impacts of oviposition behaviour on fitness, we used data for each fitness component (Figures 3C-E) to construct complete fitness landscapes as a function of the two key aspects of oviposition behaviours (female fecundity and oviposition choice; Figures 3F-H). Since the landscapes encompass the entire range of possible oviposition behaviours, they likely represent the "true" underlying landscapes for all females offered a similar choice between wheat and finger millet. Recall that females from different contexts exhibit distinct combinations of fecundity and preference (Figure 2), such that they would occupy different positions in these landscapes.

As expected, the fitness landscape for survival was relatively flat (focus on the contours, ignoring triangles; Figure 3F) - female fecundity and oviposition choice influenced offspring survival only in interaction with age and density (Table 1C, Figure S9). However, landscapes for the other two fitness components paint a more interesting dichotomy. For development rate, the landscape predicts a fitness optimum at low fecundity and low preference for finger millet; with generally rapid development at low fecundity regardless of preference (Figure 3G; fecundity and egg allocation independently alter development rate, Table 1C). In contrast, offspring production is maximized at high fecundity and strong preference for finger millet with a relatively weak impact of preference (Figure $3 \mathrm{H}$, Table $1 \mathrm{C}$ ). These contrasting predicted fitness optima for offspring development rate and total number of offspring largely reflect the underlying negative tradeoff between the two (Figure 3B, independent experimental blocks 242 in Figure S11), primarily mediated by fecundity (Figure 3A). 
bioRxiv preprint doi: https://doi.org/10.1101/2021.05.27.445916; this version posted May 28, 2021. The copyright holder for this preprint (which was not certified by peer review) is the author/funder, who has granted bioRxiv a license to display the preprint in perpetuity. It is made available under aCC-BY-NC-ND 4.0 International license.

244 Separate fitness landscapes constructed for each female context generated similar patterns, indicating 245 that the fitness landscapes are robust (Figures S12, S13). We also confirmed that the landscapes 246 accurately predict the fitness consequences of any combination of female fecundity and oviposition 247 choice. In an independent experiment, we allowed females to express their oviposition preference (used 248 to predict fitness) and measured the fitness consequences of their choice (Figure 1, Experiment 3). 249 Observed female fitness matched predictions from the original landscape (compare the triangle colour 250 with background colour, Figures 3G-I; Table S1, p > 0.05 for all three fitness parameters), even though 251 the oviposition behaviour of old HD females in this experiment was different from what we had observed 252 in Experiment 1 (comparison shown in Figure S4). Thus, fitness landscapes generated by scrambling 253 the inherent association between female fecundity and preference and fitness accurately predicted the 254 fitness consequences of diverse oviposition behaviours.

\section{Females from different contexts use alternate adaptive oviposition strategies}

257 The fitness landscapes generated above suggest two general oviposition strategies that each increase 258 different fitness components - high preference for wheat with low fecundity, or high acceptance of finger 259 millet with high fecundity. To explicitly connect prior female context with these strategies, we asked 260 whether context-dependent behaviours are consistent with either of these predicted fitness peaks. To 261 do this, we used the observed context-specific oviposition behaviours described in Figure 2, which represent females from diverse age and density contexts. We predicted the fitness outcomes for each context by overlaying the median values of female fecundity and preference onto the landscapes for each fitness component. As expected, females from different contexts were positioned widely across the landscape (Figures 3I-K). As noted earlier (Figure 2A, Table 1A), females that were older or laid many more eggs. At the same time, they also had divergent oviposition choices. In light of the fitness landscapes, we can connect these contrasting patterns, now revealed as alternate adaptive strategies. 
bioRxiv preprint doi: https://doi.org/10.1101/2021.05.27.445916; this version posted May 28, 2021. The copyright holder for this preprint (which was not certified by peer review) is the author/funder, who has granted bioRxiv a license to display the preprint in perpetuity. It is made available under aCC-BY-NC-ND 4.0 International license.

270

produce fewer, rapidly-developing offspring. Distinct oviposition behaviours thus place females close to different locally adaptive fitness peaks.

Why don't all females maximize the same component of fitness? We suggest that this is partly explained by the tradeoff between offspring number and development rate, mediated by resource availability. At high population density, offspring face strong resource competition (Sokoloff 1974), likely imposing selection for females to produce faster-developing offspring. In contrast, under conditions of resource plenty (e.g. low population density), females can afford to lay many more eggs that develop slowly. Hence, females that have experienced high density lay fewer eggs and preferentially place them in wheat, where offspring develop much faster than in finger millet. In contrast, females that have only experienced low density can increase fecundity at the cost of offspring development rate, and can hence better utilize the suboptimal finger millet patch. However, fecundity is constrained by age (older females cannot lay more eggs), further altering females' placement on the fitness landscape (Figure 3I-K). Thus, age and density contexts primarily alter female fecundity, and females accordingly modulate their oviposition resource choice to optimize either total offspring or offspring development rate.

Although the fitness landscapes were generated using females from only three contexts, we could also use them to predict fitness for other contexts (mid-aged, aged LD and aged young HD), using only their oviposition behaviours. Strikingly, females from the two "aged" contexts also present divergent outcomes, though both (young HD and young LD females) were aged for 4 weeks under identical LD conditions. Their distinct positions in the fitness landscapes are driven primarily by their distinct fecundity, indicating a long-lasting impact of early experience with high density. Aged young HD females show a dramatic reduction in offspring production (Figure 3K), but their increased preference for wheat increases offspring development rate (Figure 3J). Hence, context-specific behaviours may show context-specific maximization of distinct fitness components, some of which may tradeoff with each other. In summary, the complete fitness landscapes reveal that maternal context alters distinct fitness components by differentially influencing two key aspects of oviposition behaviour. 


\section{DISCUSSION}

Here, we present the first comprehensive analysis of the linkages between females' prior context, their

oviposition behaviour, and offspring fitness. By governing female behaviour, the contexts determine

variation in context-dependent oviposition behaviours. For instance, if we only measured offspring

development rate, we would incorrectly conclude that young LD females behave maladaptively.

However, with our approach, we used the ecological selection faced by females in their prior context

(here, high vs. low competition) to assess the adaptive consequences of their behaviour. Hence, we

infer that under conditions of resource plenty (when their offspring are unlikely to face stiff competition),

females can effectively maximize the total number of offspring even if they are slower-developing. Such

context-dependent optimization of different fitness components may also explain prior cases of apparent maladaptive resource use. For instance, flour beetles exhibit seemingly maladaptive density-dependent niche contraction in a heterogeneous habitat containing wheat and corn (a poor resource) (Parent et al. 2014). Based on our current results, we suggest that the observed preference for wheat at higher densities may reflect optimization of offspring development rate or survival; whereas at low density, females maximized total offspring production. Importantly, by explicitly considering female context, we gain the ability to predict fitness outcomes relevant to the range of conditions experienced within an individual's lifespan. Thus, our results demonstrate the lack of a single global fitness peak for oviposition behaviour, and show that a change in context can shift female behaviour towards alternative fitness peaks.

322 How generalisable is this suggested coupling between context-specific behaviour and fitness? Here, we 
- that differ both across individuals in a population and across an individuals' lifespan in many species.

In Tribolium, transitions across contexts are expected to occur in association with population growth and

that species that experience such within-lifetime changes in context may also evolve context-specific

oviposition behaviours that result in optimization of distinct fitness components. Indeed, ageing is

universal and change in competition is likely a common feature of the life history of many organisms;

both factors can impact oviposition. Mechanistically, any change in context that alters female body

condition could influence resource allocation towards competing aspects of fitness (reflecting tradeoffs),

ultimately determining oviposition behaviour (Papaj 2000; Jervis et al. 2005; Berger et al. 2008). Hence,

we can broadly frame our results to make generalized predictions about the context-dependent

optimization of fitness in light of widespread natural phenomena such as ageing and density changes

(Figure 4). Of course, the exact fitness components that face selection or trade off across contexts will

likely vary across species or environments. Even so, we suggest that the core axes that determine the impact of context on behaviour - age and density - should be widely applicable.

Our results show that females in different contexts can optimize different fitness components that trade off with each other. How does preference evolve, given that female behaviour is pulled in opposing directions across their lifetime? Broadly, frequent changes in selective context during the evolutionary history of a species could lead to the observed strong, specific associations between female context and expressed oviposition behaviour. We speculate that in T. castaneum, instead of selection acting independently on both fitness components, only offspring development rate evolves under strong selection. This is generally expected for species with a high intrinsic growth rate, such as pests and invasives (Sakai et al. 2001; Lagos et al. 2017). We further suggest that at different times during their life, females experience either intensified or relaxed selection to produce fast-developing offspring. For instance, prior work shows that larval development time in Tribolium increases under high larval or adult density (Park et al. 1939; Janus 1989). Thus, one way to increase offspring development rate under 
351 (Halliday et al. 2019). Such selection on development rate may additionally drive high preference for 352 optimal resources (here, wheat) under high competition, even within a narrow range of fecundity. 353 However, how do we explain the random preference of old HD females in this framework? One 354 possibility is that old females - especially after prolonged exposure to high density - are unable to make 355 effective choices, and therefore allocate eggs randomly. Alternatively, the surprising niche expansion by 356 old females may reflect a switch in the relative benefit of rapid offspring development in wheat, vs. the 357 cost of increased resource competition when all females in the population make a similar choice. We 358 speculate that the extended exposure of old HD females to high density crosses a threshold beyond 359 which it becomes beneficial for females to accept the suboptimal but relatively unused finger millet patch. 360 In contrast, under low competition (e.g. young LD females), selection on offspring development rate 361 should be weak, allowing females to randomly allocate their eggs across habitats. Thus, distinct 362 mechanisms may explain the convergent random preference behaviour of young LD and old HD 363 females; this hypothesis needs to be explicitly tested. Nonetheless, our data suggest that both age and 364 density have immediate impacts on fecundity, in turn altering female choice. Hence, fecundity and 365 oviposition choice are inextricable; though most prior work on female context has focused on fecundity 366 alone (Awmack \& Leather 2002; Berger et al. 2008; Halliday et al. 2019). We suggest that for dispersing 367 species that often encounter heterogeneous habitats, joint measurement of fecundity and resource 368 choice is essential to fully understand oviposition behaviour. This is particularly important if changes in either behaviour influences different fitness components in different contexts, as observed here.

371 As mentioned above, our results indicate context-specific, adaptive female oviposition choices 372 corresponding to local fitness peaks. However, we observe a surprising exception. Aged young HD 373 females - despite a 4-week exposure to low density - continued to produce fast-developing offspring 374 (which is optimal at high density) instead of increasing fecundity to maximize total offspring (which is 375 optimal at low density). This suggests a long-lasting impact of prior context on behaviour, resulting in a 376 significant reduction in lifetime reproductive success (producing $\sim 15$ fewer offspring than expected 377 under low density). The failure to increase fecundity in response to a relaxation in adult competition is 
surprising (Sonleitner 1961), because flour beetles routinely experience changes in population density that drive their population dynamics (Costantino \& Desharnais 2012) and dispersal (Ziegler 1976, 1977; Gurdasani et al. 2018). As a result, we expect flour beetles to experience strong selection to rapidly respond to changes in competition and alter oviposition behaviours. Hence, the behaviour of aged young HD females appears to be maladaptive. We speculate that early physiological changes due to high density (Forchhammer et al. 2001; Stewart et al. 2005; Ramsay et al. 2006; Assie et al. 2008; Reading \& Clark 2010) may be irreversible, preventing females from optimizing their oviposition behaviours even under favourable conditions. Such "carry-over effects" are widespread in the animal kingdom (Boonstra et al. 1998; Van Allen \& Rudolf 2013; Burgess \& Marshall 2014) and can impact the choice of the colonized habitat. Alternatively, the suboptimal suppression of fecundity may persist in the population due to weak selection, e.g. if old isolated (i.e., recently dispersed) females are rare in the normal life cycle of T. castaneum (Ziegler 1976). Further work is needed to understand this interesting phenomenon and distinguish between the various hypotheses.

Our results demonstrating context-dependent oviposition behaviour also have longer-term implications for species' evolution. For instance, reduced female preference for the ancestral or optimal resource could initiate the process of niche expansion by exposing offspring to selection in a new habitat, or by influencing the resource preference and performance of subsequent generations. We showed previously that in flour beetles, larval experience with novel resources increases later use of the same resources (Ravi Kumar et al. 2018); a pattern that is also observed in many other insects (Jermy et al. 1968; Bernays \& Weiss 1996; del Campo et al. 2001; Henniges-Janssen et al. 2011; Soler et al. 2012; exposing offspring to selection and potentially improving their performance over time. Therefore, 
bioRxiv preprint doi: https://doi.org/10.1101/2021.05.27.445916; this version posted May 28, 2021. The copyright holder for this preprint (which was not certified by peer review) is the author/funder, who has granted bioRxiv a license to display the preprint in perpetuity. It is made available under aCC-BY-NC-ND 4.0 International license.

colonize new habitats (in our case, old HD and young LD females). Hence, the prior experience and history of colonizing females may be important determinants of successful niche expansion.

In conclusion, we suggest that it is important to quantify the linkages between female experience, body condition, oviposition behaviour, and offspring fitness to enable context-informed interpretations of optimality. Although a large body of prior work has partially addressed these links, we have lacked predictive power in new environmental or individual contexts. Understanding these links is also important to successfully use oviposition behaviours for pest management, such as in the push-pull strategy (Alkema et al. 2019). Here, we show an effective and reliable way to generate broad predictions about the fitness consequences of female oviposition behaviours. By dissociating females' preference from their fecundity, one can systematically cover the entire range of phenotype values that comprise the fitness landscape, including combinations of fecundity and preference that may not be directly or easily observed. One can then predict the fitness consequences of female behaviour in new contexts, without the need to measure fitness and preference in each scenario. Studies documenting evolutionary traps already highlight the power of explicitly considering longer-term historical context to understand behaviour (Hale \& Swearer 2016; Singer \& Parmesan 2018). We suggest that considering short-term female context is similarly important for understanding female behaviours as drivers of ecological and evolutionary niche expansion.

\section{ACKNOWLEDGEMENTS}

We thank Laasya Samhita, Pratibha Sanjenbam, Rittik Deb, Shyamsunder Buddh, Sneha Garge and other members of the Agashe lab for discussion and comments on the manuscript. We thank Sumita Nanda for the beetle illustration used in figures. We acknowledge funding and support from the National Centre for Biological Sciences (NCBS-TIFR), the Department of Atomic Energy, Government of India (Project Identification No. RTI 4006) and a SERB Women Research Excellence Award (WEA/2020/000030) to DA. 


\section{AUTHOR CONTRIBUTIONS}

433 VRK and DA conceived the work; VRK, DA and GA and designed experiments; VRK and GA conducted experiments; VRK and DA analysed data and wrote the manuscript; DA acquired funding.

\section{REFERENCES}

Agosta, S.J. (2006). On ecological fitting, plant-insect associations, herbivore host shifts, and host plant selection. Oikos, 114, 556-565.

Alkema, J.T., Dicke, M. \& Wertheim, B. (2019). Context-Dependence and the Development of PushPull Approaches for Integrated Management of Drosophila suzukii. Insects, 10, 1-19. Drive Population Dynamics in Novel Habitat. Am. Nat., 181, 596-608.

Anderson, P. \& Anton, S. (2014). Experience-based modulation of behavioural responses to plant volatiles and other sensory cues in insect herbivores. Plant. Cell Environ., 1826-1835.

Assie, L.K., Brostaux, Y. \& Haubruge, E. (2008). Density-dependent reproductive success in Tribolium castaneum (Herbst) (Coleoptera: Tenebrionidae). J. Stored Prod. Res., 44, 285-289.

Awmack, C.S. \& Leather, S.R. (2002). Host Plant Quality and Fecundity in Herbivorous Insects. Annu. Rev. Entomol., 47, 817-844.

Barnes, A.I., Wigby, S., Boone, J.M., Partridge, L. \& Chapman, T. (2008). Feeding, fecundity and lifespan in female Drosophila melanogaster. Proc. R. Soc. B Biol. Sci., 275, 1675-1683.

Berger, D., Walters, R. \& Gotthard, K. (2008). What limits insect fecundity? Body size- and hypothesis. Am. Nat., 151, 451-464.

Bernays, E.A. (2001). Neural Limitations in Phytophagous Insects : Implications for Diet Breadth and 
Evolution of Host Affiliation. Annu. Rev. Entomol, 46, 703-727.

460 Bernays, E.A. \& Weiss, M.R. (1996). Induced food preferences in caterpillars: the need to identify 461 mechanisms. Entomol. Exp. Appl., 78, 1-8.

462 Binckley, C.A. \& Resetarits Jr., W. (2008). Oviposition behavior partitions aquatic landscapes along 463 predation and nutrient gradients. Behav. Ecol., 19, 552-557.

464 Bobko, S.J. \& Berkeley, S.A. (2004). Maturity, ovarian cycle, fecundity, and age-specific parturition of 465 black rockfish (Sebastes melanops). Fish. Bull., 102, 418-429.

466 Boonstra, R., Hik, D., Singleton, G.R. \& TInnikov, A. (1998). The impact of predator-induced stress on 467 the snowshoe hare cycle. Ecol. Monogr., 68, 371-394.

468 Burgess, S.C. \& Marshall, D.J. (2014). Adaptive parental effects : the importance of estimating 469 environmental predictability and offspring fitness appropriately. Oikos, 123, 769-776.

470 Butlin, R. (1987). A new approach to sympatric speciation. Trends Ecol. Evol., 2, 310-311.

471 del Campo, M.L., Miles, C.I., Schroeder, F.C., Mueller, C., Booker, R. \& Renwick, J.A. (2001). Host 472 recognition by the tobacco hornworm is mediated by a host plant compound. Nature, 411, 186$473 \quad 189$.

474 Charlery de la Masselière, M., Facon, B., Hafsi, A. \& Duyck, P.-F. (2017). Diet breadth modulates 475 preference - performance relationships in a phytophagous insect community. Sci. Rep., 7, 16934. 476 Costantino, R.F. \& Desharnais. R.A. (2012). Population Dynamics and the Tribolium Model : Genetics 477 and Demography (volume 13). Springer Science and Business Media.

478 Coulson, T., Milner-Gulland, E.J. \& Clutton-Brock, T. (2000). The relative roles of density and climatic 479 variation on population dynamics and fecundity rates in three contrasting ungulate species. Proc. 480 R. Soc. B Biol. Sci., 267, 1771-1779.

481 Craig, T.P. \& Itami, J.K. (2008). Evolution of Preference and Performance Relationships. In : 482 Specialization, Speciation and Radiation : The Evolutionary Biology of Herbivorous Insects. \{ed. 483 Tilmon, K.J.\}. University of California Press, 20-29.

484 Dethier, V. G. (1954). Evolution of Feeding Preferences in Phytophagous Insects. Evolution, 8, 33-54. 485 Dvorak, J. \& Gvozdik, L. (2010). Adaptive accuracy of temperature oviposition preferences in newts. 
Evol. Ecol., 24, 1115-1127.

487

488

489

490

491

492

493

494

495

496

497

498

499

500

501

502

503

504

505

506

507

508

509

510

511

512

Feder, J.L. \& Forbes, A.A. (2008). Host Fruit-Odor Discrimination and Sympatric Host-Race Formation. In : Specialization, Speciation and Radiation : The Evolutionary Biology of Herbivorous Insects. \{ed. Tilmon, K.J.\}. University of California Press, 101-112.

Forchhammer, M.C., Clutton-Brock, T.H., Lindström, J. \& Albon, S.D. (2001). Climate and population density induce long-term cohort variation in a northern ungulate. J. Anim. Ecol., 70, 721-729.

García-Robledo, C. \& Horvitz, C.C. (2012). Parent-offspring conflicts, "optimal bad motherhood" and the "mother knows best" principles in insect herbivores colonizing novel host plants. Ecol. Evol., $2,1446-1457$.

Good, N.E. (1936). The Flour Beetles of the genus Tribolium. No. 1488-2016-123671

Gretes, W.C., Stanwyck, E.A. \& Hanson, F.E. (2016). Innate and acquired components of oligophagy in the herbivorous lepidopteran, Manduca sexta. Entomol. Exp. Appl., 160, 259-271.

Gripenberg, S., Mayhew, P.J., Parnell, M. \& Roslin, T. (2010). A meta-analysis of preferenceperformance relationships in phytophagous insects. Ecol. Lett., 13, 383-393.

Gurdasani, K., Rafter, M.A., Daglish, G.J. \& Walter, G.H. (2018). Characterising the variables associated with Tribolium castaneum adults that initiate flight in laboratory tests: Generating predictions for the fi eld. J. Stored Prod. Res., 79, 123-131.

Gurdasani, K., Rafter, M.A., Daglish, G.J. \& Walter, G.H. (2019). The dispersal flight of Tribolium castaneum - A field test of laboratory generated predictions. J. Stored Prod. Res., 83, 25-33.

Hale, R. \& Swearer, S.E. (2016). Ecological traps : current evidence and future directions. Proc. $R$. Soc. B Biol. Sci., 283, 20152647.

Halliday, W.D., Slevan-Tremblay, I. \& Blouin-Demers, G. (2019). Do Female Red Flour Beetles Assess both Current and Future Competition during Oviposition? J. Insect Behav., 32, 181-187.

Henniges-Janssen, K., Schofl, G., Reineke, A., Heckel, D.G. \& Groot, A.T. (2011). Oviposition of diamondback moth in the presence and absence of a novel host plant. Bull. Entomol. Res., 101, 99.

Jaenike, J. (1978). On Optimal Oviposition Behavior in Phytophagous Insects. Theor. Popul. Biol., 
$356,350-356$.

514

515

516

517

518

519

520

521

522

523

524

525

526

527

528

529

530

531

532

533

534

535

536

537

538

539

Janus, M.C. (1989). Phenotypic diversity of Tribolium confusum pupae in heterogeneous environments. Entomol. Exp. Appl., 50, 281-286.

Jermy, T., Hanson, F. \& Dethier, V.G. (1968). Induction of specific food preference in Lepidopterous larvae. Entomol. Exp. Appl., 11, 211-230.

Jervis, M.A., Boggs, C.L. \& Ferns, P.N. (2005). Egg maturation strategy and its associated trade-offs : a synthesis focusing on Lepidoptera. Ecol. Entomol., 30, 359-375.

Karjalainen, J., Urpanen, O., Keskinen, T., Huuskonen, H., Sarvala, J., Valkeajärvi, P., et al. (2016). Phenotypic plasticity in growth and fecundity induced by strong population fluctuations affects reproductive traits of female fish. Ecol. Evol., 6, 779-790.

Khan, I., Prakash, A., Issar, S., Umarani, M. \& Sasidharan, R. (2018). Female Density-Dependent Chemical Warfare Underlies Fitness Effects of Group Sex Ratio in Flour Beetles. Am. Nat., 191, 306- 317 .

Lagos, M.E., White, C.R. \& Marshall, D.J. (2017). Do invasive species live faster? Mass-specific metabolic rate depends on growth form and invasion status. Funct. Ecol., 31, 2080-2086.

Lailvaux, S.P. \& Kasumovic, M.M. (2011). Defining individual quality over lifetimes and selective contexts. Proc. R. Soc. B Biol. Sci., 278, 321-328.

Lüdecke, D. (2018). sjmisc: Data and Variable Transformation Functions. J. Open Source Softw., 3, 754. Lüdecke, D. (2021). sjPlot: Data Visualization for Statistics in Social Science. R package version 2.8.7. Papaj, D.R. (2000). Ovarian dynamics and host use. Annu. Rev. Entomol., 45, 423-448.

Parent, C.E., Agashe, D. \& Bolnick, D.I. (2014). Intraspecific competition reduces niche width in experimental populations. Ecol. Evol., 4, 3978-3990.

Park, T., Miller, V. \& Lutherman, C.Z. (1939). Studies in Population Physiology. IX. The Effect of Imago Population Density on the Duration of the Larval and Pupal Staged of Tribolium confusum Duval. Ecology, 20, 365-373.

Pointer, M.D., Gage, M.J.G. \& Spurgin, L.G. (2021). Tribolium beetles as a model system in evolution and ecology. Heredity., 1-15. 
540 Price, P.W. (2003). Macroevolutionary Theory on Macroecological Patterns. Cambridge University

$541 \quad$ Press. Cambridge.

542 Proffit, M., Khallaf, M.A., Carrasco, D., Larsson, M.C. \& Anderson, P. (2015). 'Do you remember the 543 first time ?' Host plant preference in a moth is modulated by experiences during larval feeding and $544 \quad$ adult mating. Ecol. Lett., 18, 365-374.

545 R Core Team (2017). R: A language and environment for statistical computing. R Foundation for 546 Statistical Computing, Vienna, Austria.

547 RStudio Team (2020). RStudio: Integrated Development for R. RStudio, Boston, Massachusetts, USA. 548 Raitanen, J., Forsman, J.T., Kivelä, S.M., Mäenpää, M.I. \& Välimäki, P. (2014). Attraction to conspecific eggs may guide oviposition site selection in a solitary insect. Behav. Ecol., 25, 110116.

\section{1}

Ramsay, J.M., Feist, G.W., Varga, Z.M., Westerfield, M., Kent, M.L. \& Schreck, C.B. (2006). Wholebody cortisol is an indicator of crowding stress in adult zebrafish, Danio rerio. Aquaculture, 258, $565-574$. Predators and Competitors. Ecology, 70, 220-228.

Ravi Kumar, V., Issar, S. \& Agashe, D. (2018). The induction of larval resource preference in heterogeneous habitats. Ecol. Entomol., 43, 719-730.

Reading, C.J. \& Clark, R.T. (2010). The impact of density, rainfall and environmental temperature on body condition and fecundity in the common toad, Bufo bufo. Oecologia, 102, 453-459.

561 Rieger, J.F., Binckley, C.A. \& Resetarits Jr, W. (2004). Larval Performance and Oviposition Site 562 Preference along a Predation Gradient. Ecology, 85, 2094-2099. biology of invasive species. Annu. Rev. Ecol. Syst., 35, 305-332.

Sand, H. (1996). Life history patterns in female moose (Alces alces): The relationship between age, body size, fecundity and environmental conditions. Oecologia, 106, 212-220. 
Sarkar, D. (2008) Lattice: Multivariate Data Visualization with R. Springer, New York

Sarkar, D. \& Andrews, F. (2019). latticeExtra: Extra Graphical Utilities Based on Lattice. R package

version 0.6-29.

Schluter, D., Price, T.D. \& Rowe, L. (1991). Conflicting selection pressures and life history trade-offs.

Proc. R. Soc. B Biol. Sci., 246, 11-17.

Singer, M.C. (1983). Determinants of Multiple Host Use by a Phytophagous Insect Population.

Singer, M.C. \& Parmesan, C. (2018). Lethal trap created by adaptive evolutionary response to an exotic resource. Nature, 557, 238-241.

Sokoloff, A. (1972) The Biology of Tribolium (volume 1). Oxford University Press. Oxford. UK.

Sokoloff, A. (1974) The Biology of Tribolium (volume 2). Oxford University Press. Oxford. UK.

Sokoloff, A. (1977) The Biology of Tribolium (volume 3). Oxford University Press. Oxford. UK.

Soler, R., Pineda, A., Li, Y., Ponzio, C., van Loon, J.J.A., Weldegergis, B.T., et al. (2012). Neonates know better than their mothers when selecting a host plant. Oikos, 121, 1923-1934.

Sonleitner, F.J. (1961). Factors Affecting Egg Cannibalism and Fecundity in Populations of Adult

\section{3}

584

585

Tribolium castaneum Herbst. Physiol. Zool., 34, 233-255.

Stewart, K.M., Bowyer, R.T., Dick, B.L., Johnson, B.K. \& Kie, J.G. (2005). Density-dependent effects on physical condition and reproduction in North American elk: An experimental test. Oecologia, 143, 85-93.

Tabashnik, B.E., Wheelock, H., Rainbolt, J.D. \& Watt, W.B. (1981). Individual Variation in the Oviposition Preference in the Butterfly, Colias eurytheme. Oecologia, 50, 225-230.

Taff, C.C., Steinberger, D., Clark, C., Belinsky, K., Sacks, H., Freeman-Gallant, C.R., et al. (2012). Multimodal sexual selection in a warbler: Plumage and song are related to different fitness components. Anim. Behav., 84, 813-821.

Thompson, J.N. (1988). Evolutionary ecology of the relationship between oviposition preference and performance of offspring in phytophagous insects. Entomol. exp. appl, 47, 3-14.

Touchon, J.C. \& Worley, J.L. (2015). Oviposition site choice under conflicting risks demonstrates that 
aquatic predators drive terrestrial egg-laying. Proc. R. Soc. B Biol. Sci, 282, 20150376.

595 Venables, W.N. \& Ripley, B.D. (2002). Modern Applied Statistics with S, Fourth edition. Springer, New 596

York.

597 Walsh, B. \& Blows, M.W. (2009). Abundant Genetic Variation + Strong Selection = Multivariate Genetic 598 Constraints : A Geometric View of Adaptation. Annu Rev Ecol Evol Syst, 40, 41-59.

599 Wickham H (2016). ggplot2: Elegant Graphics for Data Analysis. Springer-Verlag New York.

600 Wood, C.W., Wice, E.W., Del Sol, J., Paul, S., Sanderson, B.J. \& Brodie, E.D. (2018). Constraints 601 imposed by a natural landscape override offspring fitness effects to shape oviposition decisions in 602 wild forked fungus beetles. Am. Nat., 191, 524-538.

603 Yoshioka, M., Couret, J., Kim, F., McMillan, J., Burkot, T.R., Dotson, E.M., et al. (2012). Diet and 604 density dependent competition affect larval performance and oviposition site selection in the 605 606 mosquito species Aedes albopictus (Diptera: Culicidae). Parasites and Vectors, 5, 1-11. Physiol., 23, 955-960.

610 


\section{TABLES}

612

613 Table 1. Summary of the minimal adequate models for factors explaining (A) female fecundity, (B)

614 oviposition preference (shown in Figure 2) and (C) fitness components (shown in Figure 3). In (B), 615 "preference" refers to observed female oviposition choice for finger millet; but in (C), the explanatory 616 variable "preference" refers to manipulated egg allocation to finger millet. Significant retained terms are 617 in bold.

\begin{tabular}{|c|c|c|c|c|}
\hline \multicolumn{5}{|l|}{ (A) Female fecundity } \\
\hline Starting maximal model & $\begin{array}{l}\text { Model } \\
\text { type }\end{array}$ & Explanatory terms & $\mathbf{F}$ & $\mathbf{p}$ \\
\hline \multirow[t]{2}{*}{ Fecundity age*density } & \multirow[t]{2}{*}{ ANOVA } & age & 43.39 & $<0.0001$ \\
\hline & & density & 102 & $<0.0001$ \\
\hline \multicolumn{5}{|c|}{ (B) Observed female oviposition preference } \\
\hline Starting maximal model & $\begin{array}{l}\text { Model } \\
\text { type }\end{array}$ & Explanatory terms & $\begin{array}{c}\text { Model } \\
\text { estimate }\end{array}$ & $\mathbf{p}$ \\
\hline \multirow{6}{*}{$\begin{array}{l}\text { Preference } \\
\text { age*density*fecundity }\end{array}$} & \multirow{6}{*}{$\begin{array}{l}\text { Binomial } \\
\text { GLM }\end{array}$} & fecundity & 0.025 & $<0.0001$ \\
\hline & & age & -1.900 & $<0.0001$ \\
\hline & & density & 0.380 & 0.87 \\
\hline & & fecundity*age & 0.033 & $<0.0001$ \\
\hline & & fecundity* density & -0.050 & 0.03 \\
\hline & & age* density $^{*}$ & 1.920 & $<0.0001$ \\
\hline \multicolumn{5}{|l|}{ (C) Fitness components } \\
\hline \multirow[t]{2}{*}{ Starting maximal model } & $\begin{array}{l}\text { Model } \\
\text { type }\end{array}$ & Explanatory terms & $\begin{array}{c}\text { Model } \\
\text { estimate }\end{array}$ & $\mathbf{p}$ \\
\hline & & age & 1.196 & $<0.001$ \\
\hline
\end{tabular}


bioRxiv preprint doi: https://doi.org/10.1101/2021.05.27 445916; this version posted May 28, 2021. The copyright holder for this preprint (which was not certified by peer review) is the author/funder, who has granted bioRxiv a license to display the preprint in perpetuity. It is made available under aCC-BY-NC-ND 4.0 International license.

\begin{tabular}{|c|c|c|c|c|}
\hline \multirow{8}{*}{$\left|\begin{array}{l}\text { Survival } ~ \\
\text { age }^{\star} \text { density }{ }^{\star} \text { fecundity }{ }^{*} \text { preference }\end{array}\right|$} & \multirow{8}{*}{ Binomial } & & & \\
\hline & & density & -2.022 & $<0.001$ \\
\hline & & preference & -0.003 & 0.61 \\
\hline & & fecundity & -0.01 & 0.4 \\
\hline & & density*preference & 0.033 & $<0.001$ \\
\hline & & age*fecundity & -0.071 & $<0.001$ \\
\hline & & density*fecundity & 0.106 & $<0.001$ \\
\hline & & density*preference*fecundity & -0.002 & $<0.0001$ \\
\hline & & age & -0.968 & 0.003 \\
\hline & & density & 0.545 & $<0.0001$ \\
\hline Development rate & Binomial & preference & -0.006 & $<0.0001$ \\
\hline age`density`tecundity` preterence & GLIVI & fecundity & -0.092 & $<0.0001$ \\
\hline & & age*fecundity & 0.060 & 0.001 \\
\hline \multirow{11}{*}{$\begin{array}{l}\text { Total offspring } \\
\text { age*density }{ }^{\star} \text { fecundity* preference }\end{array}$} & \multirow{11}{*}{$\begin{array}{l}\text { Poisson } \\
\text { GLM }\end{array}$} & age & 2.3980 & 0.08 \\
\hline & & density & -1.4200 & $<0.001$ \\
\hline & & preference & -0.0500 & 0.98 \\
\hline & & fecundity & 0.4490 & $<0.001$ \\
\hline & & age*preference & -0.1740 & 0.04 \\
\hline & & density*preference & 0.1766 & 0.04 \\
\hline & & age*fecundity & -0.5196 & 0.09 \\
\hline & & density*fecundity & 0.9879 & $<0.001$ \\
\hline & & preference*fecundity & 0.0080 & 0.91 \\
\hline & & age*preference*fecundity & 0.1445 & 0.03 \\
\hline & & density*preference*fecundity & -0.1454 & 0.02 \\
\hline
\end{tabular}


bioRxiv preprint doi: https://doi.org/10.1101/2021.05.27.445916; this version posted May 28, 2021. The copyright holder for this preprint (which was not certified by peer review) is the author/funder, who has granted bioRxiv a license to display the preprint in perpetuity. It is made available under ACC-BY-NC-ND 4.0 International license.

\section{FIGURES}

620

621 Figure 1. Experimental design. (A) Overview of key experiments (B) Details for experiment 2, used to 622 generate fitness landscapes as a function of female fecundity and egg allocation across resource 623 patches $(\mathrm{W}=$ wheat flour, $\mathrm{FM}=$ finger millet flour $)$.

624

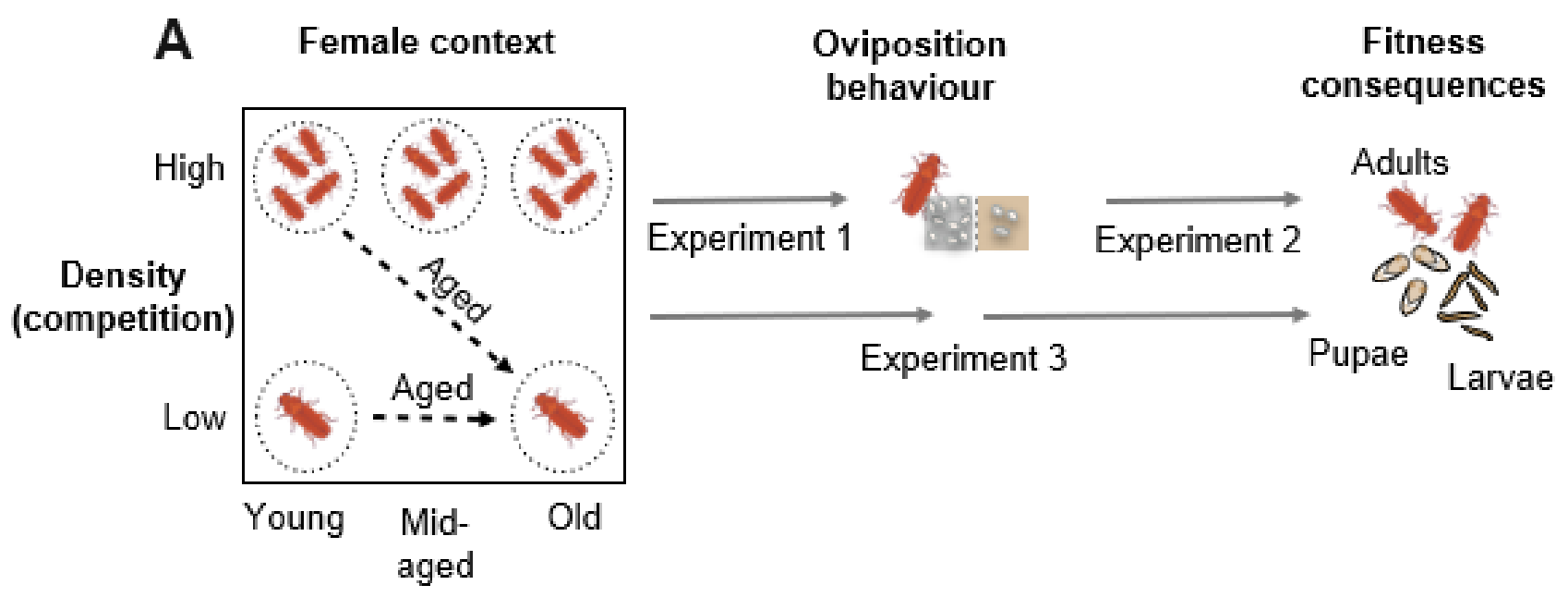

Female age

B

\section{Experiment 2}

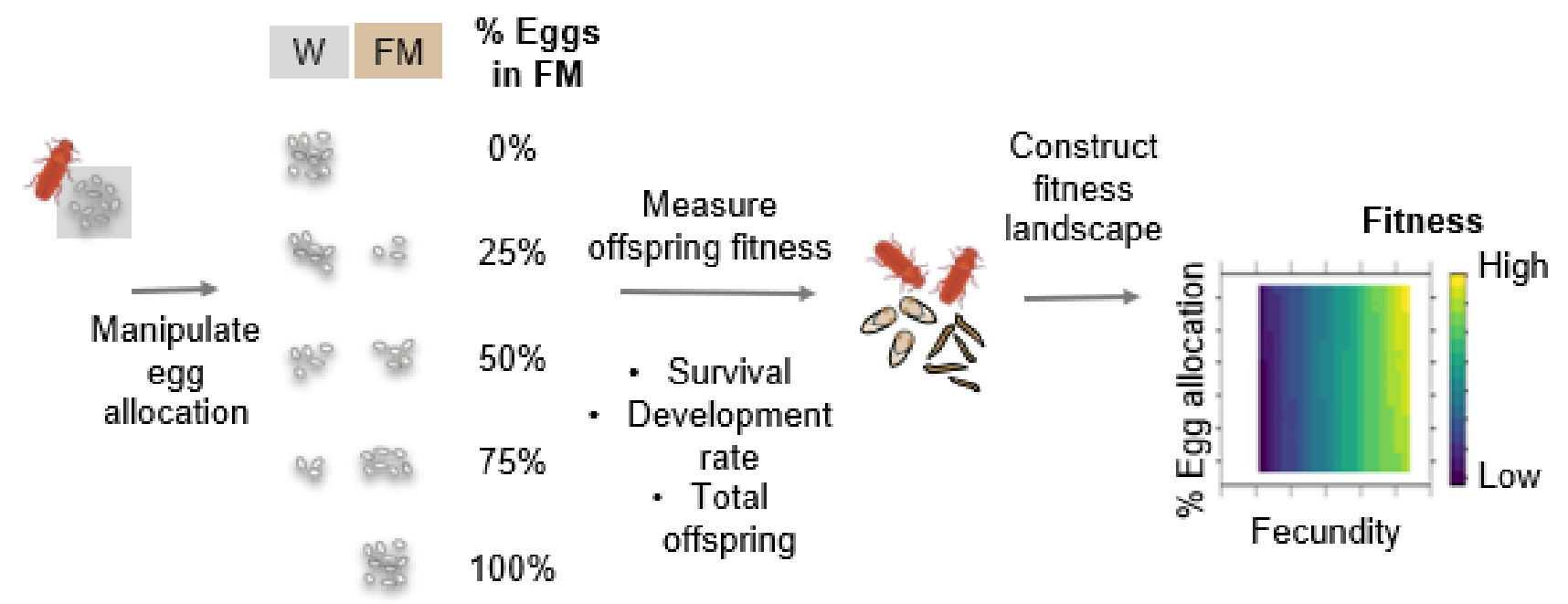

625 
626 Figure 2. Oviposition behaviours of females from different prior contexts (Experiment 1). (A) Total

627 fecundity and (B) \% Eggs laid in finger millet (FM) in a two-patch habitat ("LD": low density, "HD": high

628 density). Boxplots are coloured by female context; darker shades of a given colour represent the same 629 set of females after ageing. Boxplots connected by the same letter are not significantly different, as 630 estimated by a binomial generalized linear model. (C) Correlation between total fecundity and 631 preference for finger millet for females from each context (for aged LD females, Spearman's rho = 0.315; $632 \mathrm{~ns}=$ correlation not significant); lines indicate best-fit linear regressions for each context. Each point 633 represents data for a single female; large filled circles indicate the median fecundity and preference for 634 females from a given context; points and lines are coloured by context, as in panels A and B. 

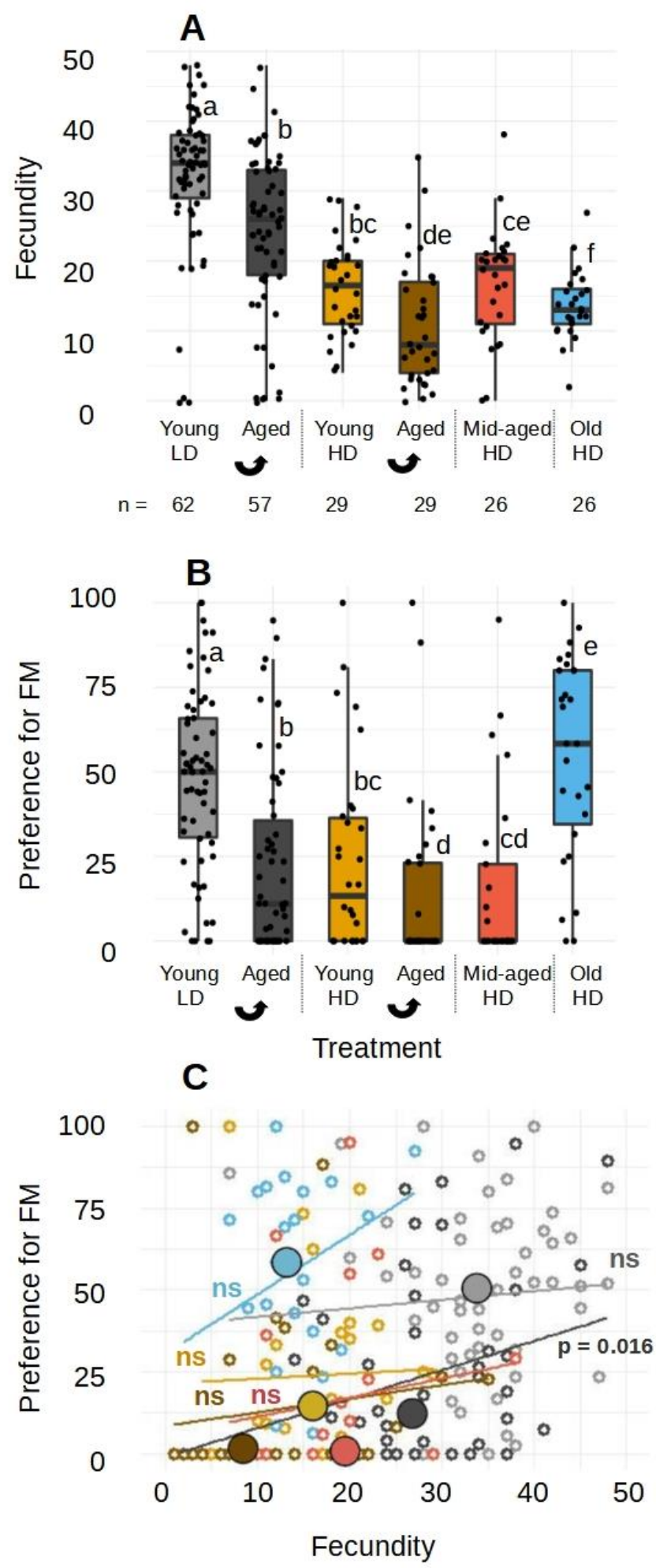

635 
639 Figure 3. Complete fitness landscapes predict the fitness consequences of female oviposition

640 behaviour in diverse contexts. Linear relationship between offspring development rate and $(A)$

641 maternal fecundity and (B) total offspring (colour scheme as in Figure 2; $n=96$ for young LD; $n=92$ for

642 young HD; $n=80$ for old HD). Each point indicates data for a single female. (C-E) Measured fitness

643 values (indicated by the z-axis color bar on the right) for individual females for each egg allocation

644 treatment (Experiment 2; $n=16-20$ per egg allocation) spanning their natural fecundity range. Points

645 are slightly jittered along the y axis for clear visualization. $(\mathrm{F}-\mathrm{H})$ Fitness landscapes generated for each

646 fitness component using loess smoothing on data shown in (C-E). For validation, landscapes are

647 overlaid with data from an independent experiment (Experiment 3) where we measured both oviposition

648 preference (which determines the position of each triangle in the landscape) and offspring fitness (which

649 determines the colour used to fill each triangle). A close match in the colour of the triangle and its

650 background indicates high predictability of fitness consequences (also see Table S1). (I-K) The same

651 fitness landscapes overlaid with median observed oviposition behaviours for females from different

652 contexts (obtained from Experiment 1, Figure 2), indicated by black filled circles. Lines connect cases

653 where the same set of females were aged (indicated by "A"). The position of each circle thus indicates 
654 the predicted fitness values for females from a given context.

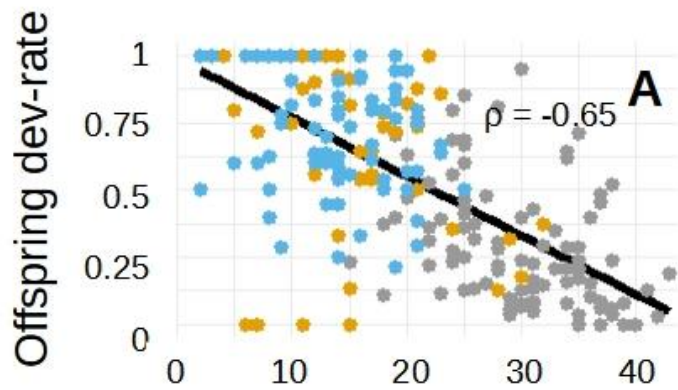

Fecundity

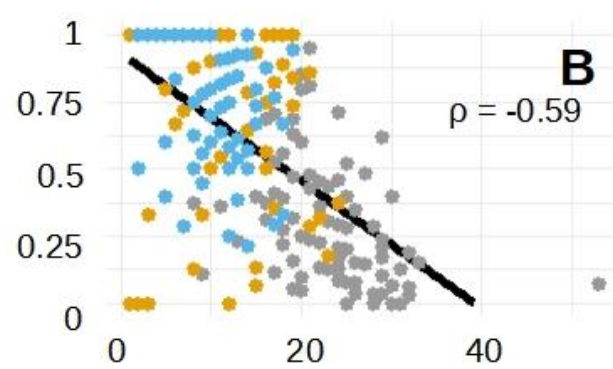

Total offspring

\section{Offspring survival}
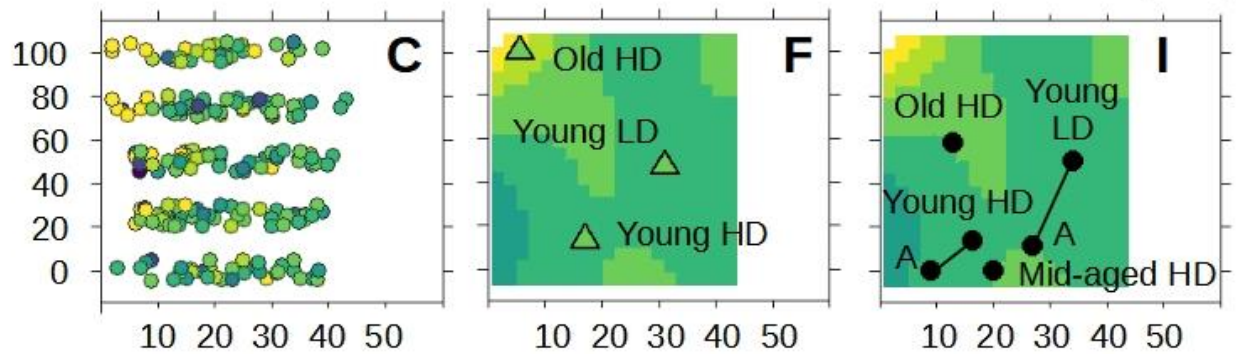

1

0.8

0.6

0.4

0.2

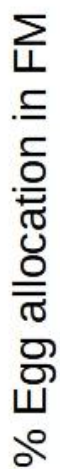
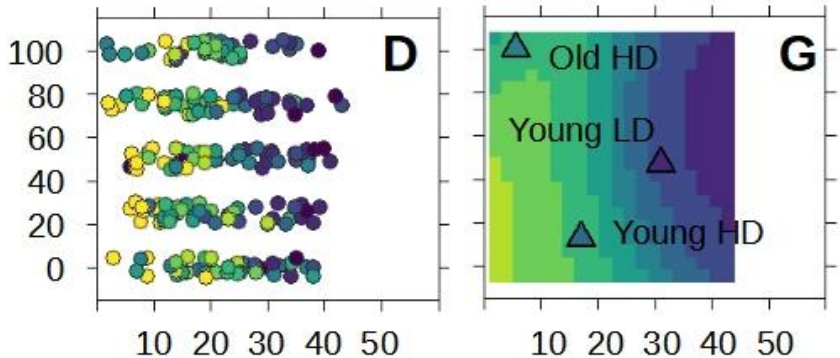

$10 \quad 2030 \quad 4050$

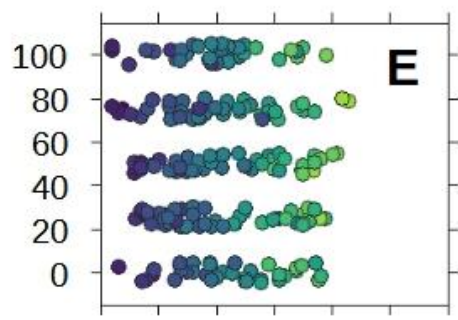

$10 \quad 20 \quad 30 \quad 4050$

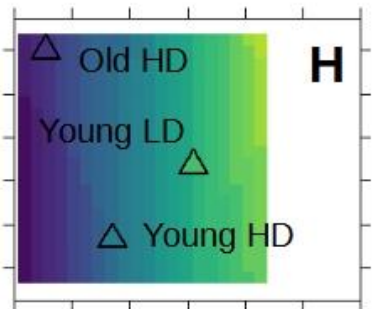

$\begin{array}{lllll}10 & 20 & 30 & 40 & 50\end{array}$

Offspring dev-rate

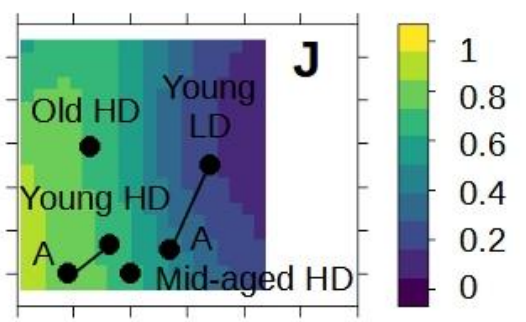

$102030 \quad 4050$

Total offspring

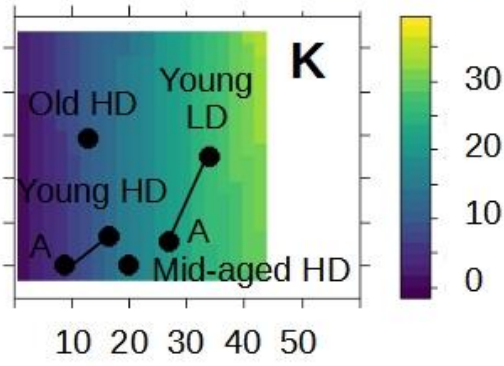

\section{Fecundity}




\section{Figure 4. Schematic showing the proposed general linkages between female context, oviposition}

661 behaviour and its fitness consequences. Young females that experience low density (bottom left)

662 may reproduce and establish a population as they age, increasing population density (top right).

663 Reproduction will give rise to young females that also experience high density (top left), which may then 664 show density-dependent dispersal, returning to a low-density condition where they can colonize a new 665 habitat (bottom left). Old females may also disperse away from high density conditions (bottom right), 666 though we do not have data on this aspect (indicated by dashed line).

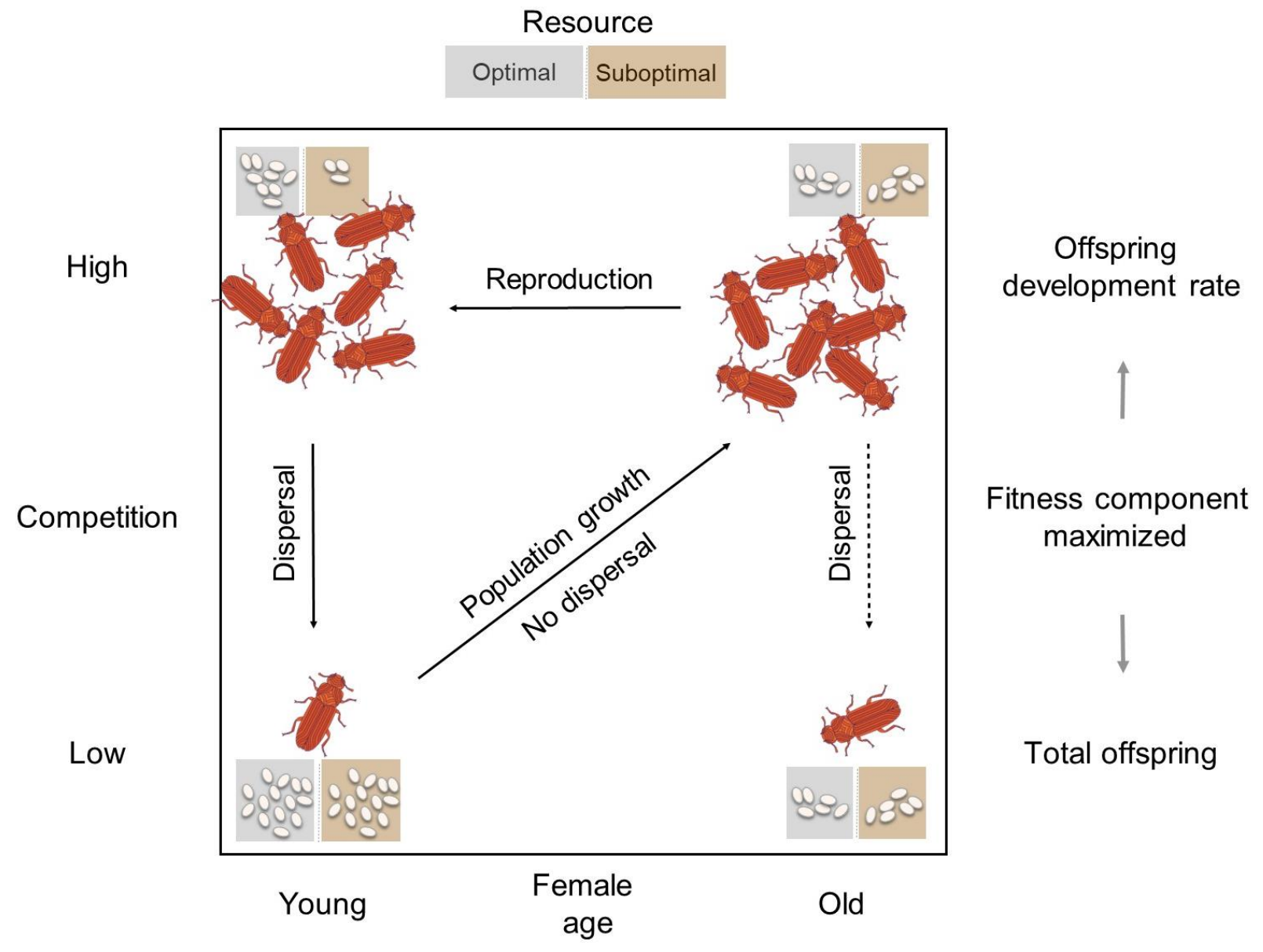

